SILICA GEL BEHAVIOR UNDER

DIFFERENT EGS CHEMICAL AND

THERMAL CONDITIONS: AN

EXPERIMENTAL STUDY

J. D. Hunt, S. M. Ezzedine, W. Bourcier, S. Roberts

January 23, 2012

Stanford Geothermal Workshop

Palo Alto, CA, CA, United States

January 30, 2012 through February 1, 2012 
This document was prepared as an account of work sponsored by an agency of the United States government. Neither the United States government nor Lawrence Livermore National Security, LLC, nor any of their employees makes any warranty, expressed or implied, or assumes any legal liability or responsibility for the accuracy, completeness, or usefulness of any information, apparatus, product, or process disclosed, or represents that its use would not infringe privately owned rights. Reference herein to any specific commercial product, process, or service by trade name, trademark, manufacturer, or otherwise does not necessarily constitute or imply its endorsement, recommendation, or favoring by the United States government or Lawrence Livermore National Security, LLC. The views and opinions of authors expressed herein do not necessarily state or reflect those of the United States government or Lawrence Livermore National Security, LLC, and shall not be used for advertising or product endorsement purposes. 
PROCEEDINGS, Thirty-Seventh Workshop on Geothermal Reservoir Engineering

Stanford University, Stanford, California, January 30 - February 1, 2012

SGP-TR-194

\title{
SILICA GEL BEHAVIOR UNDER DIFFERENT EGS CHEMICAL AND THERMAL CONDITIONS: AN EXPERIMENTAL STUDY
}

\author{
Jonathan Hunt, Souheil Ezzedine, William Bourcier, Sarah Roberts \\ Lawrence Livermore National Laboratory \\ 7000 East Avenue \\ Livermore, CA, 94550 \\ e-mail: hunt50@1lnl.gov
}

\begin{abstract}
Fractures and fracture networks are the principal pathways for migration of water and contaminants in groundwater systems, fluids in enhanced geothermal systems (EGS), oil and gas in petroleum reservoirs, carbon dioxide leakage from geological carbon sequestration, and radioactive and toxic industrial wastes from underground storage repositories. When dealing with EGS fracture networks, there are several major issues to consider, e.g., the minimization of hydraulic short circuits and losses of injected geothermal fluid to the surrounding formation, which in turn maximize heat extraction and economic production. Gel deployments to direct and control fluid flow have been extensively and successfully used in the oil industry for enhanced oil recovery. However, to the best of our knowledge, gels have not been applied to EGS to enhance heat extraction. Insitu gelling systems can either be organic or inorganic. Organic polymer gels are generally not thermostable to the typical temperatures of EGS systems. Inorganic gels, such as colloidal silica gels, however, may be ideal blocking agents for EGS systems if suitable gelation times can be achieved. In the current study, we explore colloidal silica gelation times and rheology as a function of $\mathrm{SiO}_{2}$ concentration, $\mathrm{pH}, \quad$ salt concentration, and temperature, with preliminary results in the twophase field above $100{ }^{\circ} \mathrm{C}$. Results at $25^{\circ} \mathrm{C}$ show that it may be possible to choose formulations that will gel in a reasonable and predictable amount of time at the temperatures of EGS systems.
\end{abstract}

\section{INTRODUCTION}

In enhanced geothermal systems (EGS) the reservoir permeability is often enhanced or created using hydrofracking. In hydrofracking, high fluid pressures are applied to confined zones in the subsurface usually using packers to fracture the host rock. This enhances rock permeability and therefore conductive heat transfer to the circulating geothermal fluid (e.g. water or supercritical carbon dioxide). The ultimate goal is to increase or improve the thermal energy production from the subsurface by either optimal designs of injection and production wells or by altering the fracture permeability to create different zones of circulation that can be exploited in geothermal heat extraction. Moreover, hydrofracking can lead to the creation of undesirable short-circuits or fast flow-paths between the injection and extraction wells leading to a short thermal residence time, low heat recovery, and thus a short-life of the EGS.

A potential remedy to these problems is to deploy a cementing (blocking, diverting) agent to minimize short-cuts and/or create new circulation cells for heat extraction. A potential diverting agent is the colloidal silica by-product that can be co-produced from geothermal fluids. Silica gels are abundant in various surface and subsurface applications, yet they have not been evaluated for EGS applications. In this study we are investigating the benefits of silica gel deployment on thermal response of an EGS, either by blocking short-circuiting undesirable pathways as a result of diverting the geofluid to other fractures; or creating, within fractures, new circulation cells for harvesting heat through newly active surface area contact. A significant advantage of colloidal silica is that it can be co-produced from geothermal fluids using an inexpensive membrane-based separation technology that was developed previously using DOE-GTP funding.

This co-produced silica has properties that potentially make it useful as a fluid diversion agent for subsurface applications. Colloidal silica solutions exist as low-viscosity fluids during their "induction period" but then undergo a rapid increase in viscosity (gelation) to form a solid gel. The length of the induction period can be manipulated by varying the 
properties of the solution, such as silica concentration and colloid size. We believe it is possible to produce colloidal silica solutions suitable for use as diverting agents for blocking undesirable fast-paths which result in short-circuiting the EGS once hydrofracking has been deployed. In addition, the gels could be used in conventional geothermal fields to increase overall energy recovery by modifying flow.

We believe there may be additional advantages for using colloidal silica as blocking agents. It can be inexpensively produced on site or at other geothermal sites (Figure 1); it is inorganic and environmentally friendly as opposed to organic gels often used in oil/gas industry, and unlike conventional blocking agents, the gel material might be hydraulically removed after emplacement if needed. Furthermore, colloidal silica gelation can be triggered externally, for example by mixing with salt solutions or changing the $\mathrm{pH}$, there should be fewer environmental restrictions and permitting requirements for its use given that the material originates in the same place it is to be injected, and silica removal in itself benefits the power plant in terms of silica scale control.

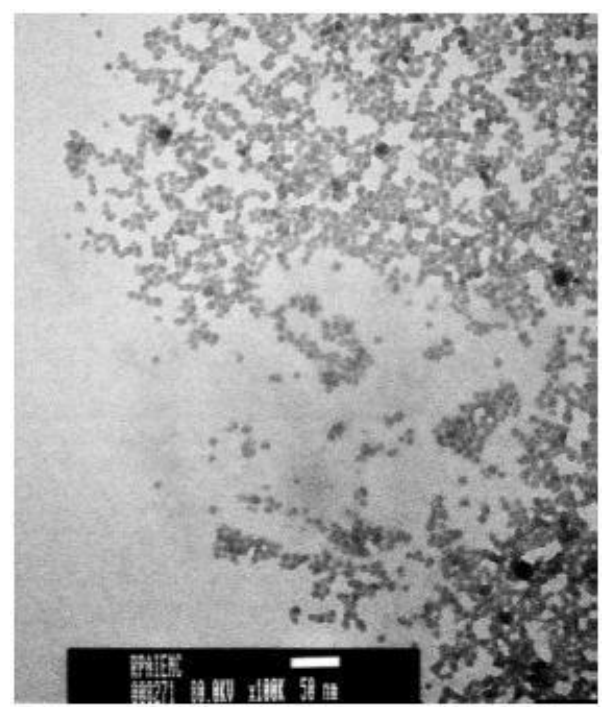

Figure 1: Silica gel produced from the Mammoth Lakes geothermal fluid. The gel is made up of a network of 10nm silica colloids.

To accurately predict when an injected geothermal fluid will set up and turn to gel, a quantitative understanding of the kinetics of silica gelation is required. Although silica gelation has been studied for decades, even the most comprehensive resources (Iler, 1979; Bergna and Roberts, 2006) provide only a qualitative understanding of the various factors $(\mathrm{pH}$, salt concentration, temperature, colloid diameter, $\mathrm{SiO}_{2}$ concentration, etc.) that influence gelation times. We did not find any quantitative method or model for predicting gel times from colloidal silica compositions. Such a method is needed to develop formulations for colloidal silica solutions for given geothermal applications. In addition, there is very little information on gel times at elevated temperatures. Because of these needs, we began an effort to acquire additional data that could be combined with the existing data to develop a more comprehensive quantitative model for use in our geothermal application.

\section{METHODS}

For our initial experiments at $25{ }^{\circ} \mathrm{C}$, we used a Sunshine Instruments Gel Time Meter (Figure 2).

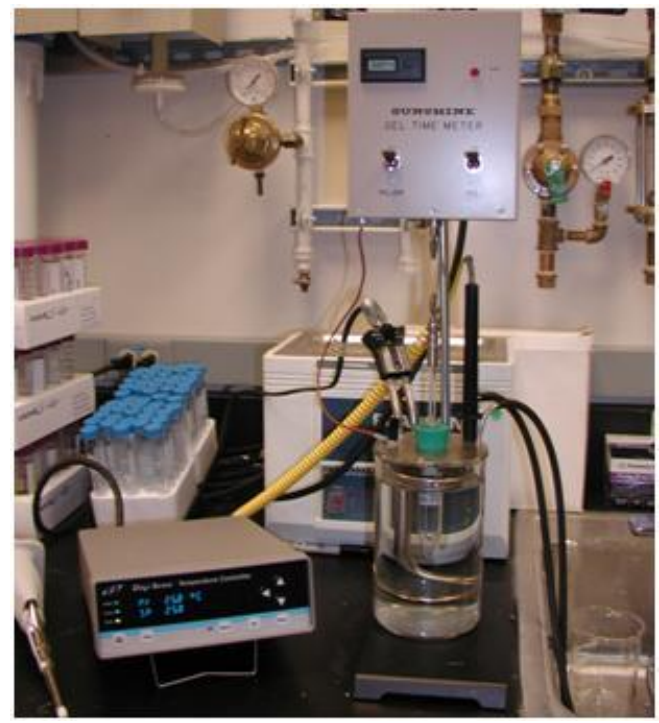

Figure 2: Sunshine Instruments Gel Time Meter (http://www.davis.com)

To use the Gel Time Meter, a sample is placed into a small polyethylene centrifuge tube which is in turn is set in a water bath. The temperature can be controlled within $1{ }^{\circ} \mathrm{C}$. A stir rod is hung from a torsion wire and immersed into the sample, which will rotate when the power to the meter is turned on. Turning the power on also starts a time counter. The lower and upper electrical contacts are set $3 / 8$ " apart. The viscosity of the sample creates a drag on the rotation of the stir rod and the lower electrical contact, bringing the two contacts closer together. At a certain threshold viscosity, the electrical contacts touch and the meter and counter shut off, recording the number of seconds between turning the meter on and reaching the threshold viscosity. This provides an accurate report of the gelation time of aqueous silica sols. The water bath can be used to bring the samples above ambient temperature, but because the stir rod must be lowered into the sample for the 
duration of the test, the water in the sample may escape due to evaporation or boiling.

The second instrument used in our experiments is a PVS rheometer from Brookfield Engineering, for experiments at elevated conditions (Figure 3). The PVS rheometer has an enclosed sample chamber, preventing sample boil-off. It can be operated up to $\sim 200{ }^{\circ} \mathrm{C}$ and $1000 \mathrm{psi}$, and can provide an accurate, quantitative measure of sample viscosity as a function of time and/or shear rate, by measuring the torque exerted on an inner cylinder inside the sample chamber. The gel time meter provided only the time to gel formation and no viscosity vs. time data. The instrument enables measurement of both simple gelation times as well as non-Newtonian behavior, e.g., thixotropy, of colloidal silica sols and gels.

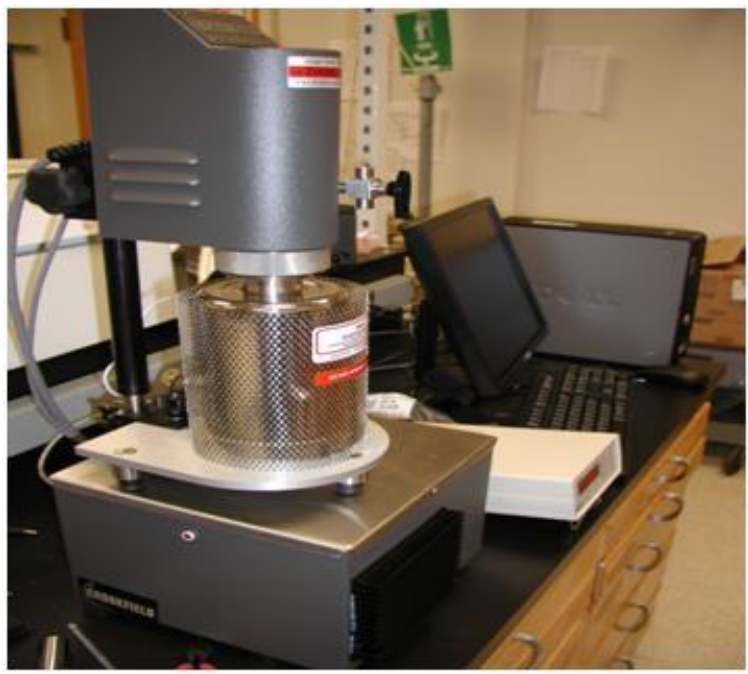

Figure 3: PVS Rheometer from Brookfield Engineering (http://www.brookfieldengineering.com) identical mixtures of colloidal silica sol, $\mathrm{NaCl}$, and $\mathrm{HCl}$, a linear relationship arises between the logarithm of gelation time and the logarithm of the silica concentration (Figure 4). While the $\mathrm{NaCl}$ concentration and $\mathrm{pH}$ are changing as the mixtures become more diluted, the molar ratio of $\mathrm{NaCl}$ to $\mathrm{SiO} 2$ and the molar ratio of added $\mathrm{HCl}$ to the $\mathrm{Na}^{+}$ stabilizer present in the colloidal sol (hereafter referred to as universal neutralization ratio or UN ratio) remains constant.

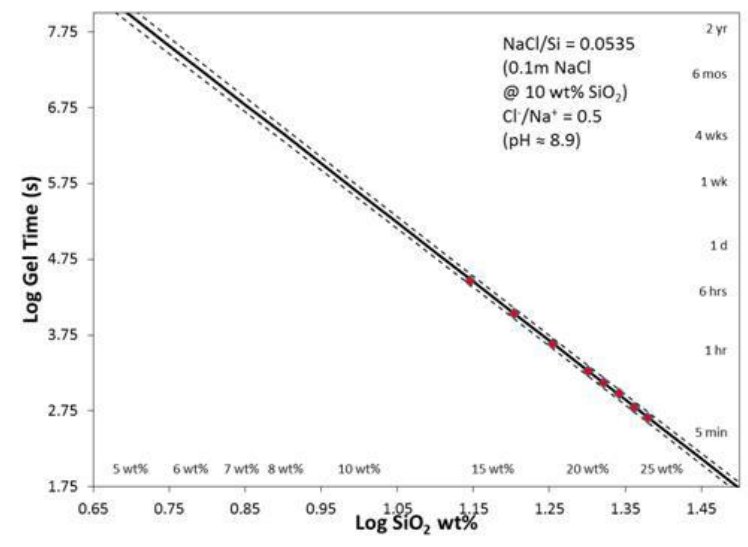

Figure 4: Log gel time vs. log silica concentration. Dashed lines are $95 \%$ confidence intervals over the entire model.

The relationship between gelation time and the molar $\mathrm{NaCl} / \mathrm{SiO}_{2}$ ratio is more complex. Increasing the amount of salt while keeping all other variables constant initially has a large, decreasing effect on gelation time, but as more salt is added, the effect is diminished. However, adding salt will always decrease the gelation time. This has been modeled as a modified hyperbolic relationship (Figure 5).

\section{RESULTS AND DISCUSSION}

\section{$\underline{\text { Gel Time Meter, } 25^{\circ} \mathrm{C}}$}

The gel time meter was used to quantitatively determine the effects of $\mathrm{SiO}_{2}$ concentration, $\mathrm{pH}$, and salt concentration on the gelation time of colloidal silica sols made with commercially available LUDOX SM-30 at $25^{\circ} \mathrm{C}$, to provide a foundation for experiments at higher temperature. The major finding of this investigation is that there is a simple and clear relationship between gelation time and $\mathrm{SiO}_{2}$ concentration. Previous investigations varied $\mathrm{SiO}_{2}$ concentration while keeping $\mathrm{pH}$ and $\mathrm{NaCl}$ concentration constant. However, if the dilution is done by adding different amounts of water to 


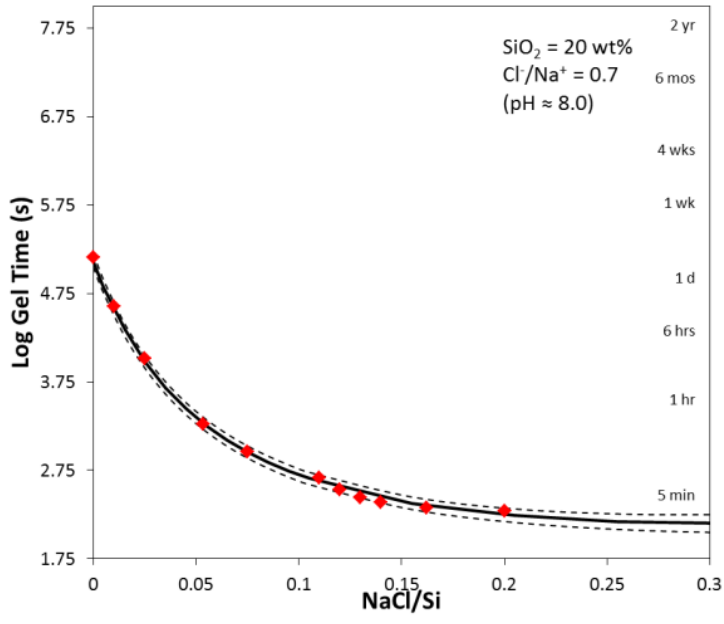

Figure 5: Log gel time vs. $\mathrm{NaCl} /$ silica ratio $(\mathrm{NaCl}$ created from the neutralization of $\mathrm{Na}^{+}$ stabilizer with $\mathrm{HCl}$ is not included in this ratio). Dashed lines are 95\% confidence intervals over the entire model.

The relationship between gelation time and UN ratio is more complex still, as there are competing ratelimiting steps at low $\mathrm{pH}$ and high $\mathrm{pH}$. Nevertheless, at near-neutral $\mathrm{pH}(6-9$; $\mathrm{UN}$ ratio $=0.5-1)$, the relationship can be modeled as a parabola (Figure 6).

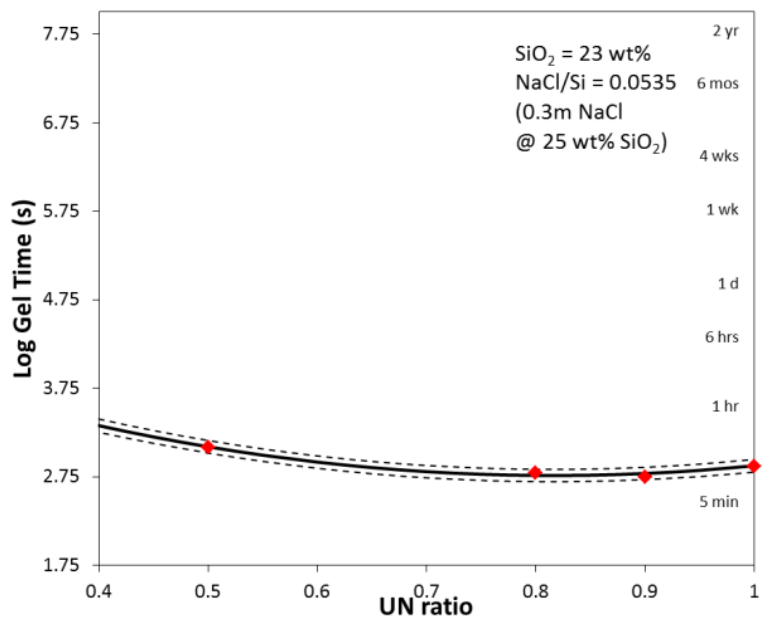

Figure 6: Log gel time vs. $\mathrm{HCl} / \mathrm{Na}^{+}$ratio (added $\mathrm{NaCl}$ is not included in this ratio). Dashed lines are 95\% confidence intervals over the entire model.
The entire dataset (91 experiments) was fitted to a single equation with 11 regression parameters, as a function of $\mathrm{SiO}_{2}$ wt\%, molar $\mathrm{NaCl} / \mathrm{SiO}_{2}$ ratio, and $\mathrm{UN}$ ratio. The dashed lines in each of Figures 4-6 represent the 2 standard deviation error for the entire regression. The regression equation $\left(\mathrm{R}^{2}=0.9973\right)$ is as follows:

$\log ($ Gel Time $(s))=A \times \log \left(\mathrm{SiO}_{2} w t \%\right)+B$

where $\mathrm{A}$ and $\mathrm{B}$ are defined as follows:

$$
\begin{gathered}
A=\frac{N a C l}{\mathrm{SiO}_{2}}\left(A_{1} U N^{2}+A_{2} U N+A_{3}\right) \\
+A_{4} U N^{2}+A_{5}
\end{gathered}
$$

$$
\begin{aligned}
B=\left(\frac{\mathrm{NaCl}}{\mathrm{SiO}_{2}}+B_{1}\right)^{-1} & {\left[\mathrm{~B}_{2} U \mathrm{~N}^{2}+B_{3}\right] } \\
& +B_{4} \frac{\mathrm{NaCl}}{\mathrm{SiO}_{2}}+B_{5} \mathrm{UN}+B_{6}
\end{aligned}
$$

The numerical values of $\mathrm{A}_{1}-\mathrm{A}_{5}$ and $\mathrm{B}_{1}-\mathrm{B}_{6}$ are given in Table 1, and the error between prediction and measurement for each experiment is shown in Figure 7. No systematic error was observed over $\mathrm{SiO}_{2}$ concentration, $\mathrm{UN}$ ratio, $\mathrm{NaCl} / \mathrm{SiO}_{2}$ ratio, or observed gelation time. While most of the parameters were fitted by linear regression, it was not possible to fit parameter $\mathrm{B}_{1}$ linearly. It was therefore fitted with non-linear regression (iterative use of Excel's solver and linear regression functions) to maximize the value of $\mathrm{R}^{2}$, and therefore does not have a welldefined error.

Table 1: $\quad$ Fitting Parameters for Equation 1.

\begin{tabular}{|c|c|c|}
\hline Parameter & Value & Error $(1 \sigma)$ \\
\hline $\mathrm{A}_{1}$ & -15.24 & 1.729 \\
\hline $\mathrm{A}_{2}$ & 26.08 & 2.585 \\
\hline $\mathrm{A}_{3}$ & 4.58 & 1.474 \\
\hline $\mathrm{A}_{4}$ & 5.40 & 0.202 \\
\hline $\mathrm{A}_{5}$ & -11.25 & 0.184 \\
\hline $\mathrm{B}_{1}$ & 0.066 & N/A \\
\hline $\mathrm{B}_{2}$ & -0.356 & 0.014 \\
\hline $\mathrm{B}_{3}$ & 0.461 & 0.010 \\
\hline $\mathrm{B}_{4}$ & -18.03 & 1.415 \\
\hline $\mathrm{B}_{5}$ & -7.21 & 0.313 \\
\hline $\mathrm{B}_{6}$ & 17.02 & 0.293 \\
\hline
\end{tabular}




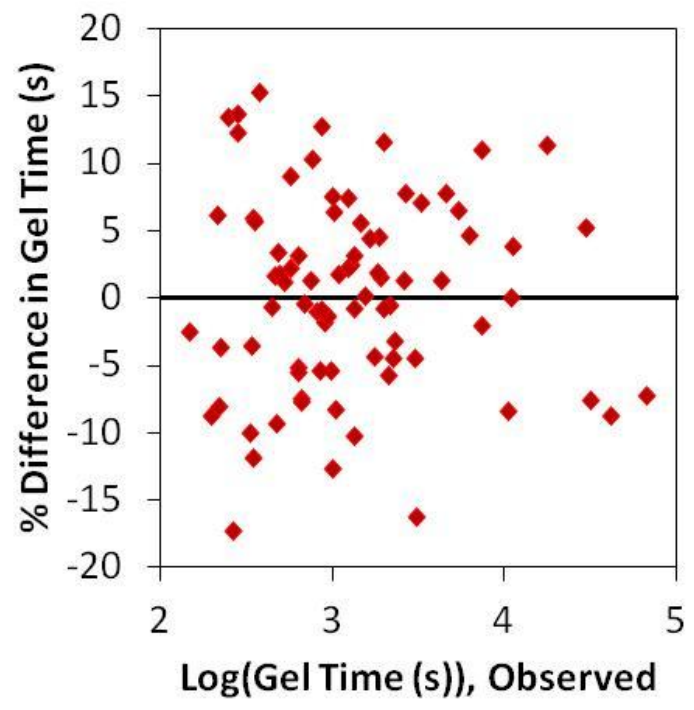

Figure 7: \% Difference in Gel Time (s) between Predicted and Observed values vs. Observed Log(Gel Time).

\section{PVS Rheometer}

Preliminary results from the rheometer indicate that gelation times can be reliably obtained from plots of viscosity over time, and that shear rate does not affect gelation time. An example of a viscosity over time plot is shown on Figure 8.

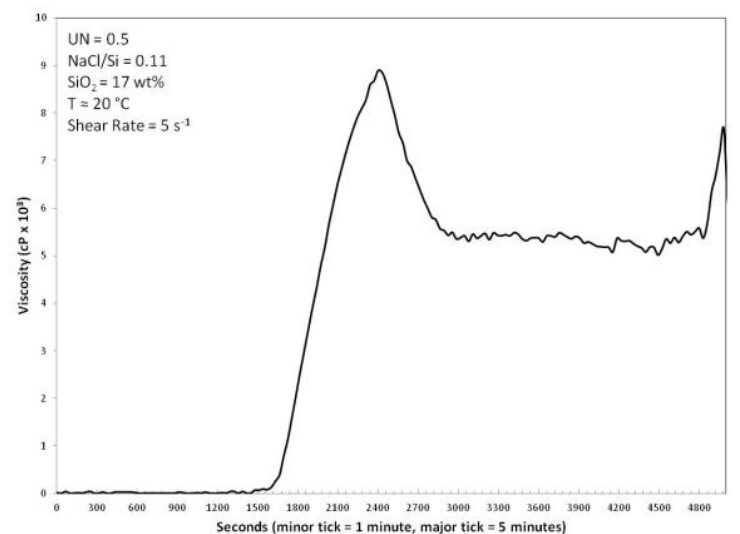

Figure 8: Viscosity $\left(c P \times 10^{3}\right)$ as a function of time (seconds), measured at room temperature at a constant shear rate of $5 \mathrm{~s}^{-1}$.

The data in Figure 8 are for a colloidal silica solution with $17 \mathrm{wt} \% \mathrm{SiO}_{2}, \mathrm{a} \mathrm{NaCl} / \mathrm{SiO}_{2}$ ratio of 0.11 , and a universal neutralization $\left(\mathrm{HCl} / \mathrm{Na}^{+}\right)$ratio of 0.5 , subjected to a continuous shear rate of $5 \mathrm{~s}^{-1}$. The viscosity remained near that for water for approximately 1600 seconds, which agrees well with the gelation time of 1634 seconds recorded by the gel time meter for the same colloidal silica solution. During the gelation process, the colloidal solution starts thickening, the viscosity increases significantly, and reaches a maximum of $9000 \mathrm{cP}$ at around 2400 seconds. After this point, the gel starts to slip past the inner cylinder rather than exerting a constant torque on it, causing the measured viscosity to drop and become irregular. However, the gel itself continues to stiffen and become brittle. Therefore, the information gathered after the maximum viscosity reached is irrelevant to this investigation.

This experiment was repeated using several different shear rates. The measured gelation time for each shear rate was within 2-3 minutes of the measured gelation time in the gel time meter; however, the maximum viscosity was dependent on the shear rate. If the shear rate doubles, the maximum viscosity recorded will be halved. This is entirely due to the interfacial layer of gel/water at the inner cylinder, and not reflective of the actual viscosity of the bulk gel as a whole. Therefore, at least in this experiment geometry, shear rate is not a significant variable when determining the gelation time.

We have started investigating the effect of temperature on gelation time using the rheometer. It is well-known that gelation time follows an Arrhenius relationship, but the values for the activation energy associated with the relationship vary within the literature, between 5 and $20 \mathrm{kcal} / \mathrm{mol}$. Preliminary results fall nearly in the middle of this range, at $12.8 \mathrm{kcal} / \mathrm{mol}$. Figure 9 shows gel times for a single solution composition measured at 25 and 75 ${ }^{\circ} \mathrm{C}$ (corrected to $63.5^{\circ} \mathrm{C}$ due to temperature ramping time), with curves representing 5, 12.5 (bolded), and $20 \mathrm{kcal} / \mathrm{mol}$ activation energies.

It should be noted that the activation energy reported here is not the true activation energy. Iler (1979) reports that as colloidal solutions are heated, the colloids grow in size to an equilibrium value. The size of the colloids will affect the gelation time independent of the temperature. The true activation energy can only be measured for a colloidal solution with colloids larger than the ultimate equilibrium value in the experiment. Nevertheless, EGS applications would only require the total effect of temperature on a given initial colloidal solution composition, which is what is reported here. 


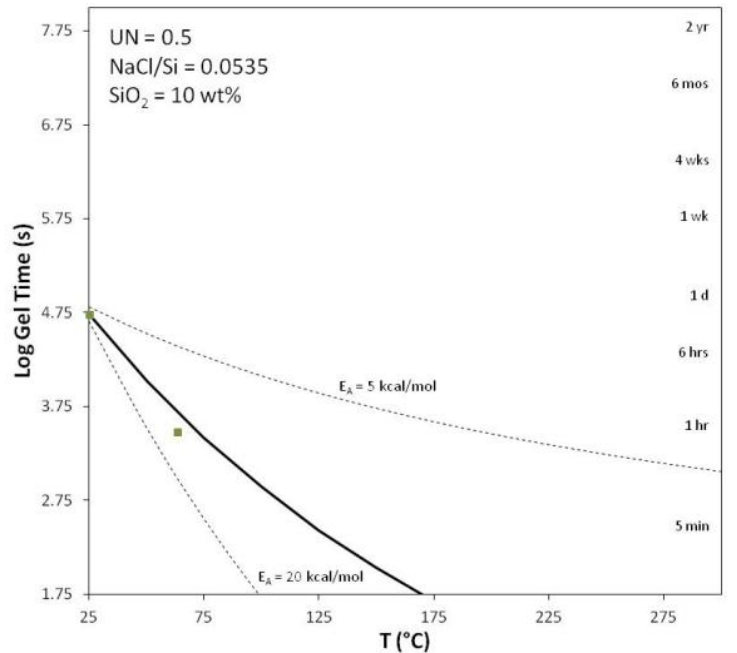

Figure 9: Arrhenius relationship of gel time vs. temperature $\left({ }^{\circ} \mathrm{C}\right) . \quad$ Bold curve corresponds to $12.5 \mathrm{kcal} / \mathrm{mol}$.

One issue that has arisen in the course of our investigation is that in some of our two-phase high temperature tests, the silica precipitates on the walls of the sample chamber as scale, rather than forming a continuous gel. It may be that at these temperatures, the kinetics of amorphous silica deposition is faster than the kinetics of gelation. This may hinder usage of colloidal silica gels in some high-T environments, however, coatings of silica deposited from concentrated colloidal silica solutions onto fracture walls can also be used to modify subsurface flow fields, if not as completely as gelation. Colloidal solutions provide a method for transporting relatively large amounts of silica to the subsurface, much larger than is possible with saturated solutions of monomeric silica.

The model outlined by Eq. 1-3, especially with the observation that the dependence of the logarithm of the gelation time on the logarithm of silica concentration is linear, can be used to predict gelation times of compositions that would take a prohibitively long time to gel at ambient conditions. Because of the Arrhenius relationship between gelation time and temperature, such a composition is necessary to provide a reasonable gelation time at EGS conditions.

\section{CONCLUSIONS}

We have made significant progress in the determination of a new candidate agent for blocking, diverting, or modifying fracture flow networks in EGS systems. Although much work at high temperature still needs to be done, results at $25{ }^{\circ} \mathrm{C}$ indicate that it may be possible to choose formulations that will gel in a reasonable and predictable amount of time at the temperatures of EGS systems. Results from this study are informing concurrent work on modeling fluid flow in rough fractures. The modeling work, illustrated in Figure 10 and described in more detail by Ezzedine et al. (this workshop), is proof-of-concept work of the positive impact of silica gel deployment.

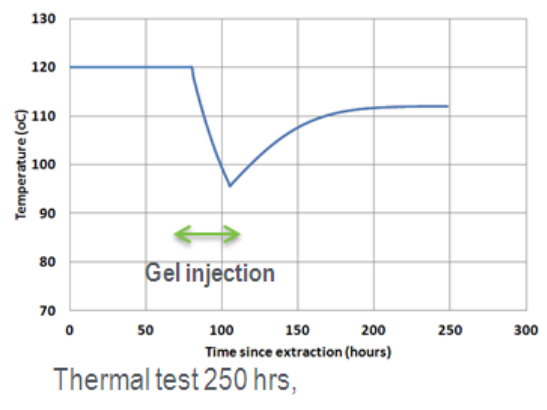

Gelation starts at $\sim 100 \mathrm{~h}$
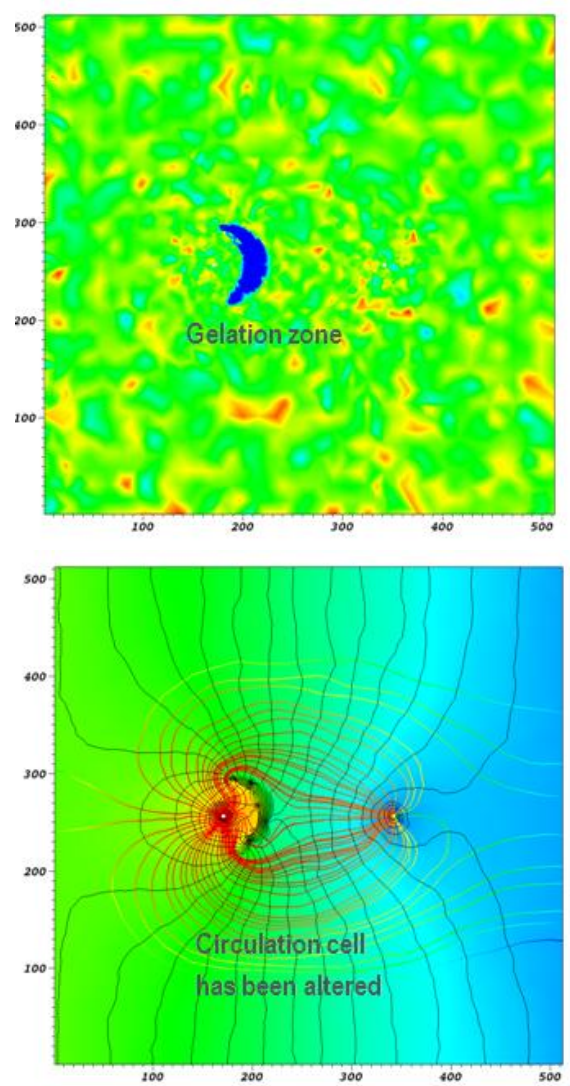

Figure 10: Two dimensional doublet flow and transport simulations of gel in a single rough fracture. Top: Temperature response at production well as a function of time. Center: Aperture field with gelled silica diverter. Bottom: Flow network showing the impact of silica gel on streamlines and flow cells. 


\section{REFERENCES}

Iler R. K., 1979. The Chemistry of Silica. Wiley.

Bergna H. E., and Roberts W. O., 2006. Colloidal Silica Fundamentals and Applications. Taylor and Francis.

Ezzedine, S. M., Hunt, J. D., Bourcier, W., and Roberts, S. K. Impact of Silica Gel Deployment on Subsurface Flow and Heat Extraction from Enhanced Geothermal Systems, Annual Stanford Workshop on Geothermal Reservoir Engineering, Stanford, Feb 2012.

This work performed under the auspices of the U.S. Department of Energy by Lawrence Livermore National Laboratory under Contract DE-AC52-07NA27344. 